\title{
BMJ Open Relationships between changes due to COVID-19 pandemic and the depressive and anxiety symptoms among mothers of infants and/or preschoolers: a prospective follow-up study from pre- COVID-19 Japan
}

Miyako Kimura (D) , ${ }^{1}$ Kazuki Kimura, ${ }^{2}$ Toshiyuki Ojima ${ }^{3}$

To cite: Kimura M, Kimura K, 0jima T. Relationships between changes due to COVID-19 pandemic and the depressive and anxiety symptoms among mothers of infants and/or preschoolers: a prospective follow-up study from preCOVID-19 Japan. BMJ Open 2021;11:e044826. doi:10.1136/ bmjopen-2020-044826

- Prepublication history and supplemental material for this paper is available online. To view these files, please visit the journal online (http://dx.doi org/10.1136/bmjopen-2020044826).

Received 15 September 2020 Revised 18 January 2021 Accepted 25 January 2021

Check for updates

(C) Author(s) (or their employer(s)) 2021. Re-use permitted under CC BY-NC. No commercial re-use. See rights and permissions. Published by BMJ.

For numbered affiliations see end of article.

Correspondence to

Dr Miyako Kimura;

mkimura@marianna-u.ac.jp

\section{ABSTRACT}

Objectives Mothers with young children are particularly vulnerable to the impacts of the lifestyle changes brought about by the COVID-19 pandemic. However, the association between such changes and maternal mental health has not been examined, and comparable preCOVID-19 baseline data were lacking. Thus, we aimed to examine the relationships between changes due to COVID-19 pandemic and the development of depressive and anxiety symptoms among mothers of infants and/or preschoolers in Japan.

Design Prospective follow-up study. The baseline survey was conducted in February 2020, and the follow-up survey was conducted in June 2020.

Setting All 47 prefectures in Japan.

Participants At the baseline, 4700 mothers of infants and/or preschoolers (0-6 years) participated in the online survey (100 respondents per prefecture); 2489 of them also participated in the follow-up survey. After excluding 203 participants with a higher risk of severe mental illness at the baseline, 2286 were included in the analysis.

Outcome measures The Kessler Psychological Distress Scale was used to measure depressive and anxiety symptoms, with a cut-off point of 13 or more. We estimated the adjusted OR (AOR) using multiple logistic regression analysis.

Results During the follow-up period, 151 (6.6\%) of respondents newly developed depressive and anxiety symptoms. Participants who experienced a shortage of relaxation time (AOR 1.61, 95\% $\mathrm{Cl} 1.06$ to 2.47), increased difficulty in child rearing (AOR $1.89,95 \% \mathrm{Cl} 1.32$ to 2.70 ), increased partner aggression (AOR 2.93, 95\% Cl 1.42 to 6.05 ) and an increased sense of unfairness (AOR 1.74, $95 \% \mathrm{Cl} 1.10$ to 2.73 ) were more likely to develop these symptoms.

Conclusions Changes in circumstances and perceptions during COVID-19 outbreak were significantly related to the development of depressive and anxiety symptoms among mothers of young children. Strategies to reduce solo parenting and increase social awareness related to domestic violence are needed.
Strengths and limitations of this study

- One of the first follow-up studies comparing mental health before and during the COVID-19 pandemic.

- Investigated the relationships between life changes due to COVID-19 pandemic and mental health.

- Mothers of infants and/or preschoolers were recruited from all 47 prefectures in Japan.

- We used online surveys, so participants only included panel members of the survey company.

- Only mental health problems that developed during COVID-19 were focused on.

\section{INTRODUCTION}

COVID-19 has altered the lives of many people, and its impact on mental health has been reported worldwide. In particular, caution should be taken with respect to maternal mental health. As a result of the COVID-19 outbreak, women may have more burdens placed on their time from various care responsibilities, and these increasing care demands may be associated with increasing stress, which can negatively affect mental health. ${ }^{1}$

On 11 March 2020, the $\mathrm{WHO}^{2}$ confirmed that COVID-19 was a pandemic, and on 7 April 2020, the Head of the Novel Coronavirus Response Headquarters in Japan declared a national state of emergency. ${ }^{3}$ Although Japan has not taken compulsory measures (eg, lockdowns), the government has requested that citizens living in the 13 prefectures designated as the 'Prefectures under Specific Cautions' stay at home and refrain from going out, moving to other prefectures or visiting downtown restaurants with hospitality services. Additionally, before WHO confirmed the pandemic, most schools 
in Japan had been required to temporarily close beginning 2 March 2020. ${ }^{4}$ Therefore, since March, the effects of the COVID-19 outbreak on parents and their children have been remarkable in Japan.

Similar situations may be seen globally, although longitudinal studies before COVID-19 are limited. Pierce et $a \tilde{l}$ pointed out that comparable pre-COVID-19 baseline data to measure changes, at both the individual and population levels, are lacking. Therefore, they conducted a secondary analysis of a national longitudinal cohort study and an online survey in April 2020, and found that women, young people and those with preschool-aged children showed significantly increased mental distress 1 month after lockdown. However, to our knowledge, studies comparing data collected just before and during the COVID-19 pandemic that focus specifically on women with young children do not yet appear in the literature. Therefore, the risk factors faced by these vulnerable populations remain unknown. Further, it is also unclear how changes due to COVID-19 situation are linked with maternal mental health.

We conducted a baseline survey (6-17 February 2020) that aimed to investigate how negative experiences were related to health and behaviour among mothers of young children across Japan. During the survey period, there had been one confirmed COVID-19 death in Japan, ${ }^{6}$ and the government had declared no pandemic-related regulations. However, a few weeks later, most schools had been closed, and from April to May, all 47 prefectures requested citizens to avoid the 'Three Cs'—closed spaces, crowded spaces and close-contact settings-under emergency measures (but without penalties imposed). ${ }^{3}$ To assess the impact of the COVID-19 pandemic on the respondents of the baseline survey, we conducted a second survey from 16 to 30 June 2020. During this period, most municipalities had decided to reopen primary, junior high and high school starting in June (including staggered attendance). However, many kindergartens and other childcare facilities in urban areas were open with reduced hours or asked parents to exercise caution and bring their children in only when absolutely necessary.

This follow-up study aimed to examine the relationships between changes due to COVID-19 pandemic and the development of depressive and anxiety symptoms among mothers of infants and/or preschoolers in Japan.

\section{METHODS}

\section{Participants and procedure}

Data were collected from online surveys hosted by a survey company that had a nationwide research panel of 4.7 million ( $48 \%$ men and $62 \%$ women, and $49 \%$ of them had children). The baseline survey was conducted from 6 to 17 February 2020, and the eligible registrants were women aged 20-49 years, and had at least one young child (0-6 years). A total of 4700 responses from all 47 prefectures in Japan (100 respondents per prefecture) were collected. The follow-up survey was conducted from

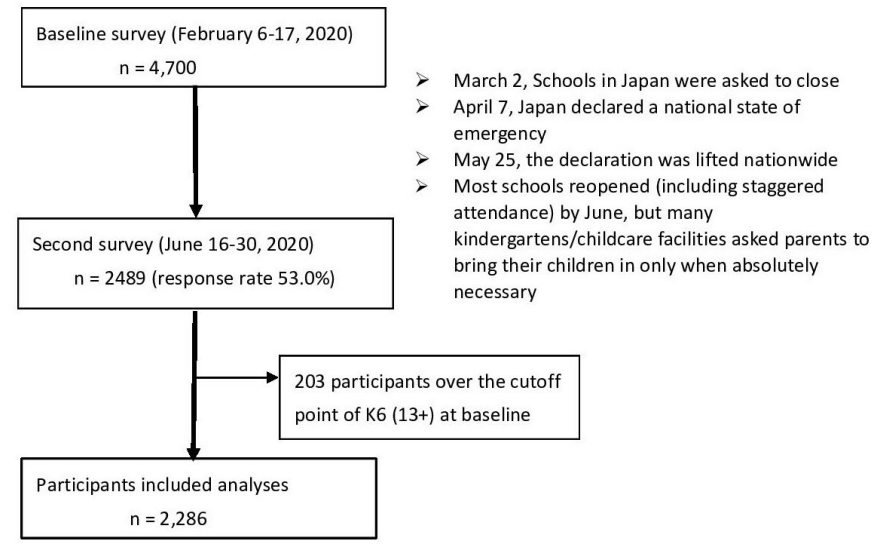

Figure 1 Flow chart of participants in the follow-up study and timeline of the COVID-19 pandemic in Japan. K6, Kessler Psychological Distress Scale.

16 to 30 June 2020 . The survey company asked the participation of the follow-up survey to the participants who completed the baseline survey. In total, 2489 participants also completed the follow-up survey (response rate 53\%). However, 203 participants of the follow-up survey were over the cut-off point of the Kessler Psychological Distress Scale $(\mathrm{K} 6 ; 13+)$ at baseline. Thus, they were excluded, and 2286 participants were included in the analysis (figure 1).

\section{Patient and public involvement}

No patient and public were involved in the design, recruitment and conduct of this study. However, the first author conducted a group interview with mothers of young children before implementing the baseline survey, and reflected their experiences to create online questionnaire of the baseline survey.

\section{Measurements}

\section{Depressive and anxiety symptoms}

The outcome variables of this study were depressive and anxiety symptoms, which were assessed using the $\mathrm{K} 6 .^{78}$ The Japanese version has been confirmed to demonstrate an equivalent performance to the original English version when used for screening purposes. ${ }^{9}$ The K6 asks respondents how often during the past 30 days they have felt nervous, hopeless, restless or fidgety, worthless, that everything was an effort and so depressed that nothing could cheer them up. Responses are rated on a 5-point Likert scale $(0=$ 'none of the time', $1=$ 'a little of the time', $2=$ 'some of the time', $3=$ "'most of the time', $4=$ 'all of the time'), and higher scores indicate more severe psychological distress. ${ }^{7}$ The Japanese version of the K6 has been found to show screening performance for mood and anxiety disorders equal to that of the Center for Epidemiologic Studies Depression Scale, and has recommended cut-off points of $4 / 5$ for mood/anxiety disorders and $12 / 13$ for severe mental illness. ${ }^{10}$ Following previous studies, ${ }^{11}{ }^{12}$ a cut-off point of 12/13 was used to assess depressive and anxiety symptoms in this study. Cronbach's alpha for this study was 0.911 , with scores ranging from 0 to 24 , with a mean score of $6.1 \quad(\mathrm{SD}=5.2)$. 


\section{Sociodemographic variables}

Sociodemographic variables included the respondents' age (20-29, 30-39, 40-49 years), annual household income in yen $(<4000000 ; 4000000-5999999 ; \geq 6000000$; do not want to answer), educational background (junior high/high school, junior college/vocational school, university/postgraduate), employment status (home maker and employed outside the home/other including self-employment), marital status (married/has partner, widowed/divorced/never married), number of children (1, 2, 3 or more) and child's age $(0-1,2-3, \geq 4$ years). If the participants had more than one child, they were requested to answer the age and other child-related survey questions with regard to their youngest child.

\section{Changes related to the COVID-19 pandemic}

Although there are various factors related to mothers' mental health, this study focused on the COVID-19 pandemic-related changes in the circumstances and perceptions of mothers from March to May 2020, as compared with February 2020. Based on potential risk factors for mental health identified in previous literature, ${ }^{15} 13-18$ we collected data from participants regarding living areas, financial difficulty, fear of COVID-19 transmission, burden of child rearing, relationships between partners and unfairness.

As noted above, 13 designated prefectures (Tokyo, Osaka, Hokkaido, Ibaraki, Saitama, Chiba, Kanagawa, Ishikawa, Gifu, Aichi, Kyoto, Hyogo and Fukuoka) requested that citizens refrain from activities such as going out or moving to other prefectures; such restrictions could be considered as possible risk factors of mental health. The participants were asked which prefecture they lived in, and answers were then dichotomised as "living in areas under special precautions' or 'not living in areas under special precautions'.

Increased financial difficulty was also regarded as a possible risk factor for mental health. Although we used baseline data for annual household income, this reflected the previous year, and therefore may not show the impacts of COVID-19. Thus, to assess respondents' perceptions of COVID-19's economic impact on their household, they were asked about their financial situation between March and May 2020: 'It became more challenging financially, compared to February'. Participants could respond to this item with either 'yes $=1$ ' or ' $\mathrm{no}=0$ '.

Having fear of COVID-19 transmission was considered another possible risk factor for maternal mental health. Previous studies have shown that women often have more caregiver responsibilities related to children and sick family members than men. ${ }^{1}$ Thus, this imbalance can lead to a higher psychological burden on women when considering the risks of disease transmission, as was reported after the 2013-2016 Ebola outbreak in West Africa. ${ }^{1}$ Therefore, we assessed respondents' fear of COVID-19 transmission using the following item, to which responses were ether 'yes' (1) or 'no' (0): 'Between March to May 2020, I suspected novel coronavirus infection whenever I noticed a slight change in my family members' physical condition or my own'.

Two aspects of the burden of child rearing were assessed: shortage of relaxation time spent with their children and increased difficulty in child rearing. Shortage of relaxation time was assessed as follows: 'Between March to May 2020, I did not have a relaxing time with my child'. Responses were 'yes $=1$ ' or 'no $=0$ '. Increased difficulty in child rearing was assessed as follows: 'I often felt that childcare was more difficult and almost unbearable between March and May than it was previously'. Responses were rated on a 4-point Likert scale (1='agree', $2=$ 'mostly agree', $3=$ 'mostly disagree', $4=$ 'disagree'), and then dichotomised as ' 1 ' for 2 and 1 , and ' 0 ' for 3 and 4 . From March to May 2020, most kindergartens and other childcare facilities were closed; thus, mothers might have spent more time caring for their children at home and not had enough time to relax. Moreover, staying at home and having limited space to play may increase stress for young children, which might be reflected in their behaviour, and, in turn, may be linked with increased maternal stress.

Relationships between partners were assessed by two aspects: increased partner's time spent at home and increased partner aggression. Increased partner's time spent at home was assessed as follows: 'Between March to May 2020, my husband/partner stayed at home more often'. Possible responses were 'yes $=1$ ' or 'no $=0$ '. Although a gender equality policy has been implemented in Japan, women had to do more housework and related works than men, and its gender gap was still considerable. ${ }^{19}$ Therefore, increase in partner's time spent at home might increase the respondents' housework and stress, which may have a link with their mental health. Whether a respondent's husband/partner was violent towards them was assessed as follows: 'Between March to May 2020, my husband/partner shouted at me more often' and 'Between March to May 2020, my husband/ partner was violent with me'. Participants could respond to both questions with either 'yes' or 'no'; however, since these responses might be considered to overlap, if the participant responded to both or either one with 'yes', we treated it as 'yes=1', and if the participant responded 'no' to both, we treated it as ' $\mathrm{no}=0$ '.

Increased sense of unfairness was assessed as follows: 'Between March to May 2020, I felt unfairness more often'. Responses were 'yes $=1$ ' or ' $\mathrm{no}=0$ '. According to Schulz et al, ${ }^{13}$ exposure to unfair treatment can be associated with psychological distress. In addition, social inequalities, discrimination and disadvantages have been shown to be related to increased mental health risk. ${ }^{14} 15$ Since social inequalities are expected to increase during the COVID-19 pandemic, ${ }^{16-18}$ this could possibly lead to an increase in one's sense of unfairness, which in turn may be associated with mental health.

To confirm a dose-response relationship between changes related to the COVID-19 pandemic and the development of depressive and anxiety symptoms, a 
total number of 7 variables (living in areas under special precautions, increased financial difficulty, having fear of COVID-19 transmission, shortage of relaxation time, increased difficulty in child rearing, increased partner aggression and increased sense of unfairness) were considered, with scores ranging from 0 to 7 . This total number was divided into four groups $(0,1,2$ and $\geq 3)$. Since increase in the partner's time spent at home was considered a protective factor, during analysis process, this variable was not included in the total number of changes.

\section{Statistical analysis}

Participants' sociodemographic variables and variables related to changes due to COVID-19 across K6 scores (cut-off: 12/13) were analysed using the $\chi^{2}$ test. Multiple logistic regression analysis was performed to calculate adjusted odds ratios (ORs) and 95\% CIs using depressive and anxiety symptoms as the dependent variables. First, sociodemographic variables and variables related to changes due to COVID-19 were included in the crude model. Model 1 included demographic variables at baseline; model 2 added socioeconomic changes (living in areas under special precautions and increased financial difficulty) to the variables in model 1; model 3 added family relationships and psychological changes (having fear of COVID-19 transmission, shortage of relaxation time, increased difficulty in child rearing, increased partner aggression and increased partner's time spent at home) to the variables in model 2; and model 4 added increased sense of unfairness to the variables in model3. In model 5, model 1 (sociodemographic variables at baseline) was added to the number of changes related to COVID-19. There were no missing data. IBM SPSS V.22 was used for all statistical analyses, with a $p$ value of 0.05 set as the significance level.

\section{RESULTS}

At baseline, the prevalence of depressive and anxiety symptoms was $8.2 \%$ (387/4700). Among the 4700 participants, 2489 participated in the second survey, and its prevalence of depressive and anxiety symptoms was 9.9\% (247/2489). Their prevalence at baseline was $8.2 \%$ (203/2489), which was the same as a whole, and increased during 4 months ( $\mathrm{p}=0.006)$. Among the 203 participants, 96 were still over the cut-off $(\mathrm{K} 6 \geq 13)$, but 107 were improved $(\mathrm{K} 6<13)$ at the second survey. After excluding these 203 participants, $151(6.6 \%)$ of the 2286 participants were considered to have newly developed depressive and anxiety symptoms during the follow-up period (online supplemental material 1). Table 1 shows the participants' characteristics in relation to depressive and anxiety symptoms. Mean participant age was 35.3 years $(\mathrm{SD} \pm 5.5$, range $20-49)$, and mean child age was 2.5 years $(\mathrm{SD} \pm 2.0$, range $0-6$ years). Table 2 shows the ORs and 95\% CIs of possible risk for depressive and anxiety symptoms. In model 1 , there was no relationship between sociodemographic variables at baseline and newly developed depressive and anxiety symptoms. In model 2, increased financial difficulty was related to newly developed depressive and anxiety symptoms (adjusted OR (AOR) 1.73, 95\% CI 1.21 to 2.50), while living in areas under special precautions did not. In model 3, shortage of relaxation time, increased difficulty in child rearing and increased partner aggression were 1.73-3.24 times more likely to be associated with developing depressive and anxiety symptoms. Contrastingly, increased partner's time spent at home was less likely to be associated with the development of depression and anxiety ( 0.55 times). In model 4 , increased sense of unfairness was more likely to be associated with the development of depressive and anxiety symptoms (AOR 1.74, 95\% CI 1.10 to 2.73); however, the significant relation between increased financial difficulty and depressive and anxiety symptoms was weakened (AOR $1.43,95 \%$ CI 0.97 to 2.10). In this model, shortage of relaxation time (AOR $1.61,95 \%$ CI 1.06 to 2.47 ), increased difficulty in child rearing (AOR 1.89, 95\% CI 1.32 to 2.70) and increased partner aggression (AOR 2.93, 95\% CI 1.42 to 6.05 ) were more likely to develop depressive and anxiety symptoms. However, increased partner's time spent at home was less likely to develop depressive and anxiety symptoms (AOR $0.54,95 \%$ CI 0.35 to 0.84 ), which did not include the total number of changes in model 5 . In the final model, experiencing three or more changes related to COVID-19 (excluding increased partner's time spent at home) was more likely to be associated with the development of depressive and anxiety symptoms (AOR 3.68, 95\% CI 2.20 to 6.18$)$.

\section{DISCUSSION}

To the best of our knowledge, this is the first follow-up study that examines the relationships between changes due to COVID-19 and the newly developed depressive and anxiety symptoms among mothers of young children in Japan. From baseline to the follow-up period, 6.6\% of respondents newly developed depressive and anxiety symptoms, which might be related to changes in circumstances due to COVID-19 pandemic. Although various studies reported that socioeconomic factors are related to mental health, ${ }^{20}$ this study did not show a significant relationship between respondents' sociodemographic variables at baseline and newly developed depressive and anxiety symptoms. In addition, living in areas under special precautions and having fear of COVID-19 transmission were not significantly related to newly developed depressive and anxiety symptoms. This might be partially explained by Japanese policy. Although special precaution areas asked citizens to avoid the Three Cs and temporary close their own shops, restaurants, and so on, there were no lockdown policies or related penalties. Therefore, although such circumstances can increase stress, it was not related to the development of more severe mental health disorders. Furthermore, as of 1 July 2020, there were no COVID-19-related deaths in Japan among 
Table 1 Characteristics of the participants in relation to depressive and anxiety symptoms $(n=2286)$

\begin{tabular}{|c|c|c|c|c|c|c|c|c|c|}
\hline \multirow[b]{3}{*}{ Variables } & \multirow{2}{*}{\multicolumn{2}{|c|}{ Total }} & \multicolumn{4}{|c|}{$\begin{array}{l}\text { Newly developed depressive and } \\
\text { anxiety symptoms }\end{array}$} & \multirow[b]{3}{*}{ df } & \multirow[b]{3}{*}{$\mathrm{X}^{2}$} & \multirow[b]{3}{*}{$P$ value } \\
\hline & & & \multicolumn{2}{|c|}{$\begin{array}{l}\text { No }(K 6<13) \\
n=2135(93.4 \%)\end{array}$} & \multicolumn{2}{|c|}{$\begin{array}{l}\text { Yes }(K 6 \geq 13) \\
n=151(6.6 \%)\end{array}$} & & & \\
\hline & $\mathbf{n}$ & $\%$ & $\mathbf{n}$ & $\%$ & $\mathbf{n}$ & $\%$ & & & \\
\hline \multicolumn{10}{|l|}{ Age (years) } \\
\hline $20-29$ & 352 & 15.4 & 328 & 15.4 & 24 & 15.9 & 2 & 2.926 & 0.232 \\
\hline $30-39$ & 1396 & 61.1 & 1296 & 60.7 & 100 & 66.2 & & & \\
\hline $40-49$ & 538 & 23.5 & 511 & 23.9 & 27 & 17.9 & & & \\
\hline \multicolumn{10}{|l|}{ Educational background } \\
\hline Junior high/high school & 613 & 26.8 & 577 & 27.0 & 36 & 23.8 & 2 & 0.733 & 0.693 \\
\hline Junior college/vocational school & 781 & 34.2 & 727 & 34.1 & 54 & 35.8 & & & \\
\hline University/postgraduate & 892 & 39.0 & 831 & 38.9 & 61 & 40.4 & & & \\
\hline \multicolumn{10}{|l|}{ Marital status } \\
\hline Married/has partner & 2176 & 95.2 & 2035 & 95.3 & 141 & 93.4 & 1 & 1.157 & 0.282 \\
\hline Widowed/divorced/never married & 110 & 4.8 & 100 & 4.7 & 10 & 6.6 & & & \\
\hline \multicolumn{10}{|l|}{ Employment status } \\
\hline Home maker & 1081 & 47.3 & 1011 & 47.4 & 70 & 46.4 & 1 & 0.056 & 0.813 \\
\hline Employed outside the home/self-employment & 1205 & 52.7 & 1124 & 52.6 & 81 & 53.6 & & & \\
\hline \multicolumn{10}{|l|}{ Annual household income (yen) } \\
\hline$<4000000$ & 518 & 22.7 & 481 & 22.5 & 37 & 24.5 & 3 & 4.073 & 0.254 \\
\hline $4000000-5999999$ & 628 & 27.5 & 580 & 27.2 & 48 & 31.8 & & & \\
\hline$\geq 6000000$ & 708 & 31.0 & 672 & 31.5 & 36 & 23.8 & & & \\
\hline Not answered & 432 & 18.9 & 402 & 18.8 & 30 & 19.9 & & & \\
\hline \multicolumn{10}{|l|}{ Number of children } \\
\hline 1 & 1007 & 44.1 & 937 & 43.9 & 70 & 46.4 & 2 & 1.352 & 0.509 \\
\hline 2 & 899 & 39.3 & 838 & 39.3 & 61 & 40.4 & & & \\
\hline 3 or more & 380 & 16.6 & 360 & 16.9 & 20 & 13.2 & & & \\
\hline \multicolumn{10}{|l|}{ Child's age (years) } \\
\hline $0-1$ & 1211 & 53.0 & 1137 & 53.3 & 74 & 49.0 & 2 & 1.108 & 0.575 \\
\hline $2-3$ & 589 & 25.8 & 548 & 25.7 & 41 & 27.2 & & & \\
\hline 4 or more & 486 & 21.3 & 450 & 21.1 & 36 & 23.8 & & & \\
\hline \multicolumn{10}{|l|}{ Living in areas under special precautions } \\
\hline Yes & 779 & 34.1 & 727 & 34.1 & 52 & 34.4 & 1 & 0.009 & 0.923 \\
\hline No & 1507 & 65.9 & 1408 & 65.9 & 99 & 65.6 & & & \\
\hline \multicolumn{10}{|l|}{ Increased financial difficulty } \\
\hline Yes & 537 & 23.5 & 486 & 22.8 & 51 & 33.8 & 1 & 9.514 & 0.002 \\
\hline No & 1749 & 76.5 & 1649 & 77.2 & 100 & 66.2 & & & \\
\hline \multicolumn{10}{|l|}{ Having fear of COVID-19 transmission } \\
\hline Yes & 536 & 23.4 & 492 & 23.0 & 44 & 29.1 & 1 & 2.918 & 0.088 \\
\hline No & 1750 & 76.6 & 1643 & 77.0 & 107 & 70.9 & & & \\
\hline \multicolumn{10}{|l|}{ Shortage of relaxation time } \\
\hline Yes & 319 & 14.0 & 280 & 13.1 & 39 & 25.8 & 1 & 18.983 & $<0.001$ \\
\hline No & 1967 & 86.0 & 1855 & 86.9 & 112 & 74.2 & & & \\
\hline \multicolumn{10}{|l|}{ Increased difficulty in child rearing } \\
\hline Yes & 895 & 39.2 & 807 & 37.8 & 88 & 58.3 & 1 & 24.828 & $<0.001$ \\
\hline No & 1391 & 60.8 & 1328 & 62.2 & 63 & 41.7 & & & \\
\hline \multicolumn{10}{|l|}{ Increased partner aggression } \\
\hline Yes & 54 & 2.4 & 42 & 2.0 & 12 & 7.9 & 1 & 21.864 & $<0.001$ \\
\hline
\end{tabular}




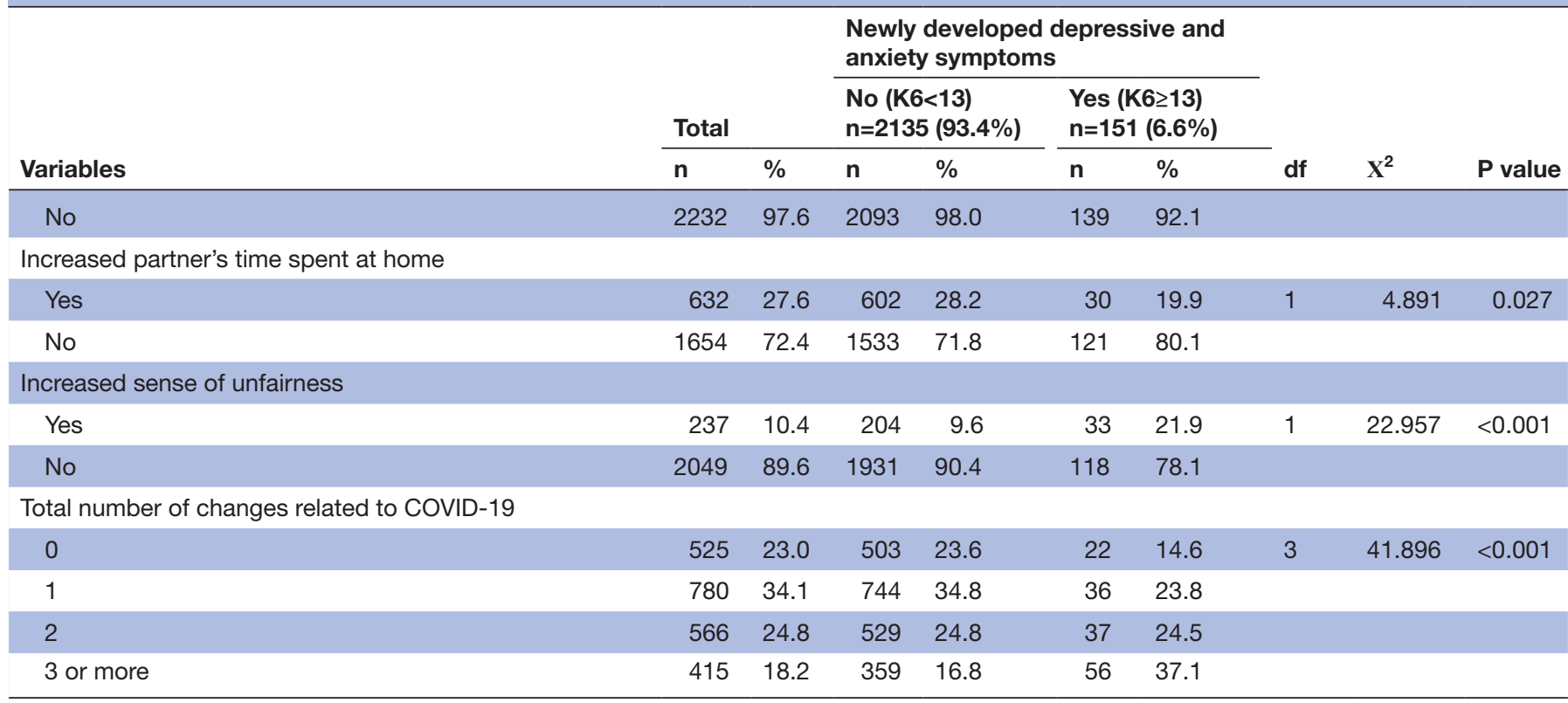

Differences were tested using the $\mathrm{X}^{2}$ test. K6, Kessler Psychological Distress Scale.

individuals under 10 , while the number of deaths among those in their 20s, 30s and 40s was 1, 4 and 14, respectively. ${ }^{21}$ Since these numbers indicated a low COVID-19 mortality risk for individuals similar in age to the mothers in our study and their children, having fear of COVID-19 transmission was not strongly linked with their mental health. One remarkable finding was that annual household income at baseline did not relate to mental health, despite increased financial difficulty during the pandemic being found to be related to mental health.

Increased parenting burden was significantly related to the development of depressive and anxiety symptoms. During March to May, many kindergartens and other facilities were closed, while others were open with reduced hours or asked parents to exercise caution and bring their children in only when absolutely necessary. Thus, mothers may have been required to care for their children all day, when they had not done so prior to the COVID-19 outbreak. This may relate to a shortage of relaxation time among mothers who showed worsened mental health at follow-up. This result followed the prediction of the World Bank Group ${ }^{1}$ that women will have more burdens placed at their time due to increased care responsibilities during COVID-19, which could negatively affect their ability to fully participate in the labour market and impact their mental health. In addition, children may also experience stress, and some may present challenging behaviour, which could increase difficulties in child rearing that, in turn, may be related to poor mental health. Similar findings underpinned a population survey in the UK, in which people living with preschoolers were found to be especially vulnerable to mental health issues during COVID-19. ${ }^{5}$ Furthermore, Peek and Fothergill ${ }^{22}$ conducted research following Hurricane Katrina, and suggested that parents' understanding of their mental and emotional states was influenced by their children's ability to build a sense of routine and normalcy. However, in the case of the COVID-19 pandemic, children and adults struggle to create normalcy and have a long-term vision for the future. Such uncertainty in one's goals during the COVID-19 pandemic may contribute to mothers' negative perceptions about child rearing. Therefore, reducing solo parenting and providing flexible parenting support are needed to mitigate maternal difficulties related to childcare.

Increased partner aggression from March to May was significantly related to newly developed depressive and anxiety symptoms. Increasing intimate partner violence during COVID-19 has been reported worldwide, ${ }^{23}{ }^{24}$ and our results also followed such trends. However, $2 \%$ of the respondents in the group without depressive and anxiety symptoms and $7.9 \%$ in the group with these symptoms reported an increase in aggressive behaviour from their partners. This seems to be lower than in other countries, which may be partially related to the lack of lockdown policies in Japan. For example, increases in intimate partner violence (as demonstrated by increases in emergency calls and helpline use) since lockdowns were put in place were reported in Argentina (25\%), Cyprus (30\%) and Singapore (33\%). ${ }^{24}$ Moreover, the present study focused on mothers of young children, and nearly half of the respondents had one child between the ages of 0 and 1 year. Therefore, our study participants may have been married for only a short period of time, and thus had fewer opportunities to face violence than women who have been married for longer. A recent report in Japan 


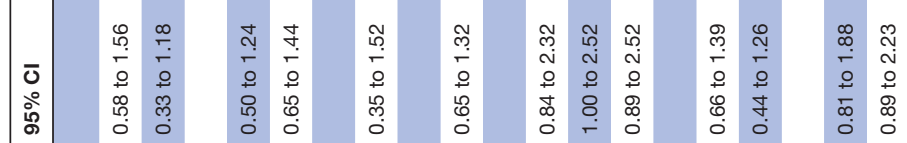

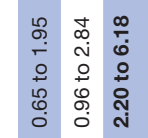

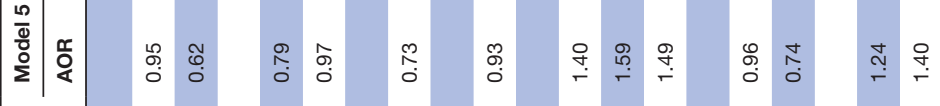

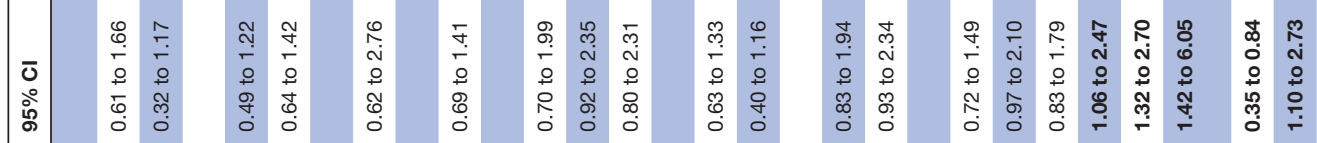

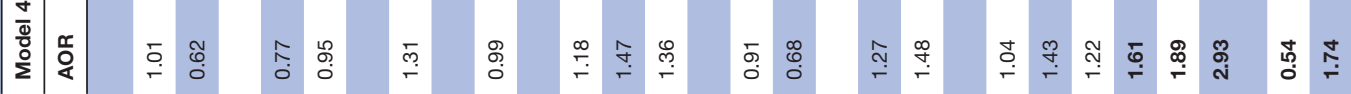

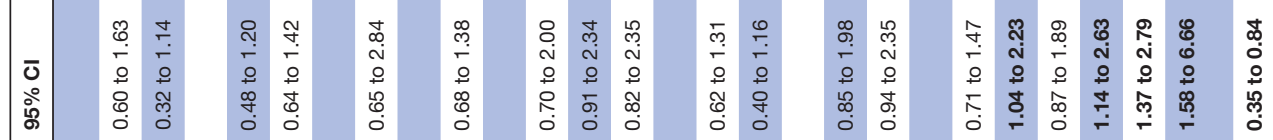

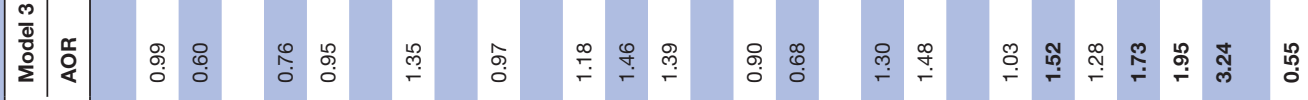

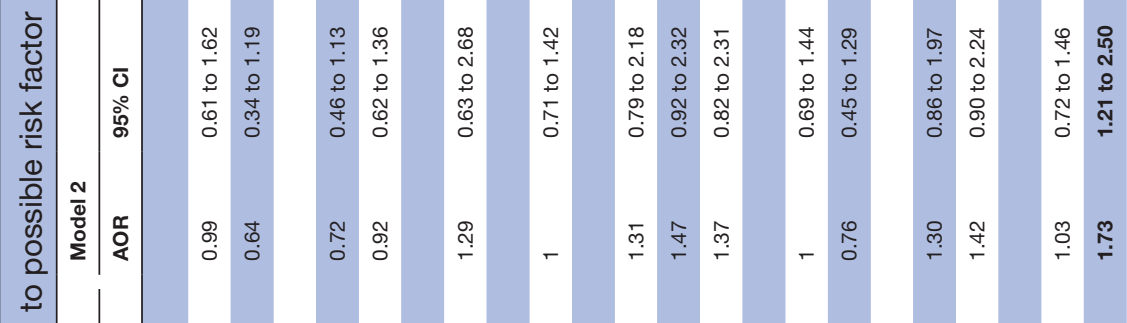

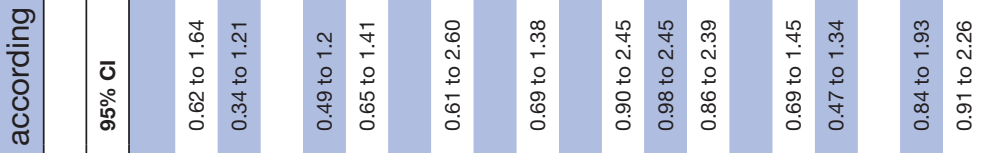

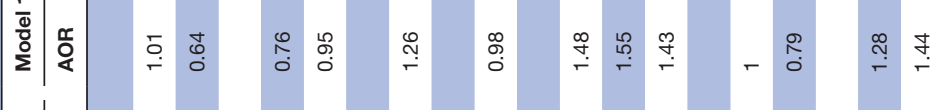

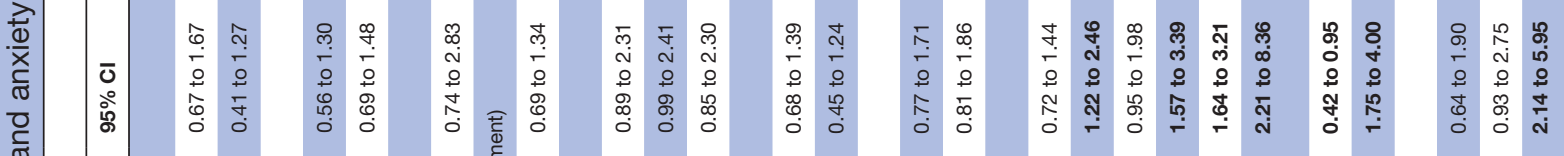

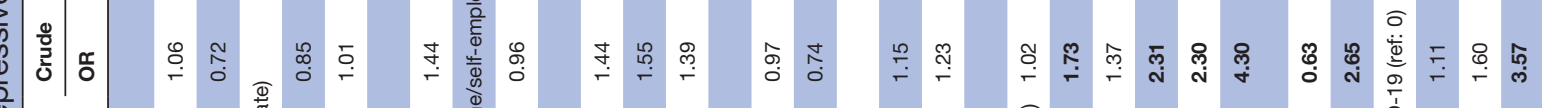

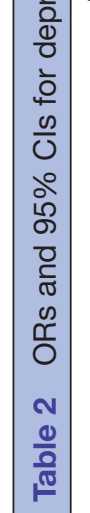

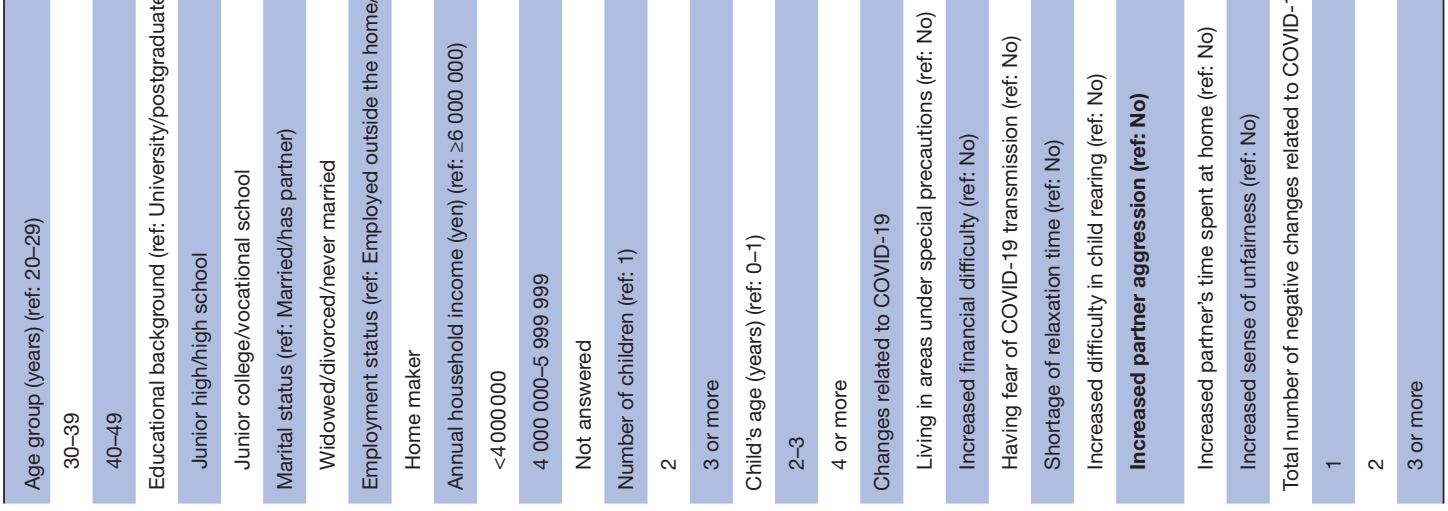


showed that $31.3 \%$ of women have experienced some type of domestic violence ${ }^{25}$; thus, national rates of domestic violence in general do not seem to be low. Although the rate of increased partner aggression was not high, mothers of young children might find it more difficult to escape from their homes and partners than other groups. Thus, information on the consequences of facing aggressive behaviour from a partner (eg, poor mental health) should be disseminated within the wider population (eg, in workplaces and childcare facilities) to increase awareness, and specific strategies targeted towards men, such as providing them with information related to anger control and maternal mental health, may be needed.

One unexpected finding was that having a partner who spent more time at home had a negative association with newly developed depressive and anxiety symptoms, which could be regarded as one of possible protective factors for maternal mental health. Some people worked remotely while staying at home from April to May, and they might have also needed to care for their children more frequently. Most respondents $(71.8 \%$ without increased depressive and anxiety symptoms group and $80.1 \%$ with increased symptoms) reported that their partners did not increase the time they spent at home, even under emergency conditions. This may imply that when kindergartens and childcare facilities were closed, the majority of mothers had to care for their young children at home, 24 hours/day. In addition, if the time a partner stays at home increases, but they do not participate in housework and childcare at all, it may have a negative psychological effect on mothers. Thus, the positive aspect of increasing time spent at home and the importance of a husband/ partner's involvement in housework and childcare should be emphasised.

After entering the variable of increased sense of unfairness, the significant relationship between increased financial difficulty and depressive and anxiety symptoms disappeared. Therefore, there is a possibility that increased financial difficulty resulting from COVID-19 could have increased participants' sense of unfairness, which may be related to the development of depressive and anxiety symptoms. Furthermore, in model 4, most variables of AOR decreased, which might also be explained by perceived unfairness. In other words, if mothers perceive that they are treated fairly by their families and in society, it might positively reflect on their mental health. Thus, during the COVID-19 pandemic currently overwhelming the world, there needs to be a focus on reducing social inequality.

Finally, participants who experienced three or more changes related to COVID-19 (excluding increased partner's time spent at home) were more likely to develop depressive and anxiety symptoms. This may show the dose-response relationship between changes related to the COVID-19 pandemic and the onset of depressive and anxiety symptoms. If multiple changes lead to severe mental health issues among mothers, these circumstances may also affect the mental health of their family members. For example, fathers of young children might have similar experiences as their partners (eg, increased financial difficulty, shortage of relaxation time, increased difficulty in child rearing) and might additionally need to take care of their partners with severe mental health issues, which may lead to their own poor mental health status. Since paternal mental health has received insufficient attention as compared with maternal mental health, the association between changes during the COVID-19 pandemic and the mental health of fathers of young children should be examined.

\section{CONCLUSION}

This study examined the relationships between changes due to COVID-19 pandemic and the newly developed depressive and anxiety symptoms among mothers of young children based on the changes due to COVID-19 pandemic in Japan. Changes in circumstances and perceptions resulting from COVID-19 may be linked with the onset of depressive and anxiety symptoms, rather than socioeconomic factors identified at baseline. Reducing solo parenting and social inequality is necessary to improve maternal mental health. Additionally, to protect against partner aggression, specific strategies targeting men and raising social awareness are required. Finally, further research is needed to investigate paternal mental health and protective factors for maternal mental health during COVID-19.

\section{Limitations}

We conducted online surveys, and only individuals who were panel members of the survey company were invited to participate, making selection bias unavoidable. In addition, this study only focused on severe mental health problems developed during COVID-19, did not show mild or moderate levels of mental health problems and removed participants with previous severe mental health problems from the baseline survey. Therefore, comprehensive mental health status and their related factors among mothers of young children were not shown in this study. In addition, since we did not focus on the trend for the prevalence of mental health status, in-depth analyses of this should be reported later. Children's growth and development and being a parent can influence the relationship status and other aspects of life that also relate to maternal mental health, of which we could not adjust all these confounders. Thus, this study design does not allow for isolating the effect of COVID-19 on maternal mental health and we could not refer to causal conclusion as to the effect of COVID-19 on maternal mental health. Moreover, although data were collected across Japan, the response rate of the follow-up survey was $53.0 \%$, which may have introduced some selection bias and reduced the generalisability of this study. As noted above, the participants may have struggled with childcare during the follow-up survey, leading to the decline of the response rate. Furthermore, since we were unable to ask 
what type of unfairness the participants experienced or when they perceived unfairness, we could not provide a deeper understanding of the concept of unfairness as it was related to respondents in this study.

\section{Author affiliations}

${ }^{1}$ Department of Preventive Medicine, St Marianna University School of Medicine, Kawasaki, Kanagawa, Japan

${ }^{2}$ Faculty of Applied Life Science, Nippon Veterinary and Life Science University, Musashino, Tokyo, Japan

${ }^{3}$ Department of Community Health and Preventive Medicine, Hamamatsu University School of Medicine, Hamamatsu, Shizuoka, Japan

Acknowledgements The authors thank everyone who participated in the survey.

Contributors MK designed and conducted the research, led the statistical analysis and drafted the manuscript. KK contributed to implementation of research and to data analysis and interpretation. T0 contributed to data analysis and interpretation, and providing critical feedback to the manuscript. All authors read and approved the final version of the manuscript.

Funding This work was supported by Japan Society for the Promotion of Science, KAKENHI grant number JP $17 \mathrm{H} 02612$.

Competing interests None declared.

Patient consent for publication Not required.

Ethics approval This study was conducted after an ethical review at St. Marianna University School of Medicine. Respondents could only access the questionnaires after providing informed consent at the start of the online survey. Furthermore, respondents were also informed that they had the opportunity to withdraw from the survey at any time.

Provenance and peer review Not commissioned; externally peer reviewed.

Data availability statement № additional data are available.

Supplemental material This content has been supplied by the author(s). It has not been vetted by BMJ Publishing Group Limited (BMJ) and may not have been peer-reviewed. Any opinions or recommendations discussed are solely those of the author(s) and are not endorsed by BMJ. BMJ disclaims all liability and responsibility arising from any reliance placed on the content. Where the content includes any translated material, BMJ does not warrant the accuracy and reliability of the translations (including but not limited to local regulations, clinical guidelines, terminology, drug names and drug dosages), and is not responsible for any error and/or omissions arising from translation and adaptation or otherwise.

Open access This is an open access article distributed in accordance with the Creative Commons Attribution Non Commercial (CC BY-NC 4.0) license, which permits others to distribute, remix, adapt, build upon this work non-commercially, and license their derivative works on different terms, provided the original work is properly cited, appropriate credit is given, any changes made indicated, and the use is non-commercial. See: http://creativecommons.org/licenses/by-nc/4.0/.

ORCID iD

Miyako Kimura http://orcid.org/0000-0002-2833-3777

\section{REFERENCES}

1 World Bank Group. Gender dimensions of the COVID-19 pandemic, 2020. Available: http://documents.worldbank.org/curated/en/ 618731587147227244 [Accessed 10 Aug 2020].

2 World Health Organization. Timeline of WHO's response to COVID-19., 2020. Available: https://www.who.int/news-room/detail/ 29-06-2020-covidtimeline [Accessed 10 Aug 2020].

3 Ministry of Health, Labour and Welfare. Basic policies for novel coronavirus disease control by the government of Japan (summary) March 28, 2020 (revised on April 16, 2020). Available: https://www. mhlw.go.jp/content/10900000/000624436.pdf [Accessed 10 Aug 2020].

4 Ministry of Education, Culture, Sports, Science and Technology (MEXT). Information on MEXT's measures against COVID-19. Available: https://www.mext.go.jp/en/mext_00006.html [Accessed 10 Aug 2020].

5 Pierce M, Hope H, Ford T, et al. Mental health before and during the COVID-19 pandemic: a longitudinal probability sample survey of the UK population. Lancet Psychiatry 2020;7:30308-4.

6 Ministry of Health, Labour and Welfare. Current situation of coronavirus disease 2019 (COVID-19) and the responses of Ministry of health, labour and welfare, as of 17thFebruary, 2020. Available: https://www.mhlw.go.jp/stf/newpage_09571.html [Accessed 10 Aug 2020].

7 Kessler RC, Andrews G, Colpe LJ, et al. Short screening scales to monitor population prevalences and trends in non-specific psychological distress. Psychol Med 2002;32:959-76.

8 Kessler RC, Barker PR, Colpe LJ, et al. Screening for serious mental illness in the general population. Arch Gen Psychiatry 2003;60:184-9.

9 Furukawa TA, Kawakami N, Saitoh M, et al. The performance of the Japanese version of the K6 and $\mathrm{K} 10$ in the world mental health survey Japan. Int J Methods Psychiatr Res 2008;17:152-8.

10 Sakurai K, Nishi A, Kondo K, et al. Screening performance of K6/K10 and other screening instruments for mood and anxiety disorders in Japan. Psychiatry Clin Neurosci 2011;65:434-41.

11 Min JW, Lee SH. Validation of the K6/K10 scales of psychological distress and their optimal cutoff scores for older Koreans. Int J Aging Hum Dev 2015;80:264-82.

12 Nakamura M, Miura A, Nagahata T, et al. Low zinc, copper, and manganese intake is associated with depression and anxiety symptoms in the Japanese working population: findings from the eating habit and well-being study. Nutrients 2019;11:847.

13 Schulz A, Williams D, Israel B, et al. Unfair treatment, neighborhood effects, and mental health in the Detroit metropolitan area. $J$ Health Soc Behav 2000;41:314-32.

14 Sheppard M. Mental health and social justice: gender, race and psychological consequences of unfairness. Br J Soc Work 2003;2002:779-97.

15 World Health Organization. Social determinants of mental health. Geneva: World Health Organization, 2014.

16 Furceri D, Loungani P, Ostry JD. Will Covid-19 affect inequality? Evidence from past pandemics. Covid Economics 2020;12:138-57.

17 Dosi G, Fanti L, Virgillito ME. Unequal societies in usual times, unjust societies in pandemic ones. $J$ Indust Business Economic 2020;47:371-89.

18 United Nations Development Programme. Coronavirus vs. inequality, 2020. Available: https://feature.undp.org/coronavirus-vs-inequality/ [Accessed 10 Aug 2020].

19 Statistic Bureau, Ministry of Internal Affairs and Communications. Survey on time use and leisure activities, 2016. Available: http:// www.stat.go.jp/english/data/shakai/2016/pdf/timeuse-a2016.pdf [Accessed 10 Aug 2020].

20 Pieh C, Budimir S, Probst T. The effect of age, gender, income, work, and physical activity on mental health during coronavirus disease (COVID-19) lockdown in Austria. J Psychosom Res 2020;136:110186.

21 Ministry of Health, Labour and Welfare. Coronavirus disease 2019 (COVID-19) situation within the country. Available: https://www.mhlw. go.jp/content/10906000/000645700.pdf [Accessed 1 Sep 2020].

22 Peek L, Fothergill A. Displacement, gender, and the challenges of parenting after Hurricane Katrina. Nwsa J 2008;20:69-105.

23 UN Women. Impact of COVID-19 on violence against women and girls and service provision: rapid assessment and findings, 2020. Available: https://www.unwomen.org/en/digital-library/publications/ 2020/05/impact-of-covid-19-on-violence-against-women-and-girlsand-service-provision [Accessed 1 Sep 2020].

24 UN Women. COVID-19 and ending violence against women and girls, 2020. Available: https://www.unwomen.org/-/media/headquarters/ attachments/sections/library/publications/2020/issue-brief-covid-19and-ending-violence-against-women-and-girls-en.pdf?la=en\&vs= 5006 [Accessed 1 Sep 2020].

25 Gender Equality Bureau Cabinet Office. Data about violence from partner, 2019. Available: http://www.gender.go.jp/policy/no_violence/ e-vaw/data/pdf/dv_data.pdf [Accessed 1 Sep 2020]. 